DOI: $10.1515 /$ lpts-2016-0012

\title{
DEVELOPMENT OF MATHEMATICAL MODELS FOR DETECTING MICRON SCALE VOLUMETRIC DEFECTS IN THIN FILM COATINGS
}

\author{
G. Gaigals, M. Donerblics, G. Dreifogels \\ Ventspils University College, \\ 101 Inženieru Str., Ventspils, LV-3601, LATVIA \\ gatis.gaigals@venta.lv
}

\begin{abstract}
The focus of the present research is to investigate possibilities of volumetric defect detection in thin film coatings on glass substrates by means of high definition imaging with no complex optical systems, such as lenses, and to determine development and construction feasibility of a defectoscope employing the investigated methods. Numerical simulations were used to test the proposed methods. Three theoretical models providing various degrees of accuracy and feasibility were studied.
\end{abstract}

Keywords: deconvolution, compressive sampling, $\ell_{1}$ minimization, $n u-$ meric simulation, thin film coatings.

\section{INTRODUCTION}

To assess the quality and usability of a glass substrate covered with thin film coating it is of utmost importance to detect positions of volumetric defects, if any present, in said coatings. To do this rapidly, in manufacturing setting an automated process for detecting micron scale volumetric defects is necessary. Mechanically, the following process can be proposed: the sample (glass substrate covered with thin film coating) is fed (by a conveyer) to a test station where one side of the sample is uniformly illuminated. A sensor of some sort is positioned on the other side of the sample. If no defects are present - the sensor should produce a uniform reading. If a defect is present in the sample, it should produce a non-uniform reading from the sensor, which shall allow for determination of a defect position. In this paper, three methods for detecting position of micron scale volumetric defects, two using a onepixel camera as a sensor and one using a pixel matrix, are proposed and tested by means of numeric simulation.

\section{THEORETICAL BASIS}

Convolution. In imaging, if no optical devices, such as lenses, are used, the result sampled from a sensor can be viewed as convolution between function $f(x)$, 
which describes intensity of light reflected off or emitted from the object being photographed, and the visibility function $g(x)$, set by parameters of the sensor (pixel). The continuous time convolution (mathematically marked as operator ) of two functions $f(x)$ and $g(x)$ in one-dimensional (1D) case is an integral, when function $g(x)$ is mirrored and shifted over $f(x)$ [1]. Often the integral is taken over infinite time; however, for real world applications finite time variation is used:

$$
f(x) * g(x)=\int_{0}^{t} f(y) g(x-y) d y
$$

In two-dimensional (2D) occasion, discrete convolution (operator $\bigotimes$ ) is given by formula:

$$
f(x, y) \otimes g(x, y)=\sum_{s=-a}^{a} \sum_{t=-b}^{b} f(s, t) g(x-s, y-t) .
$$

In signal processing, convolution also describes the multiplication of spectra from two signals [2]. The definition of convolution suggests that the opposite - the reconstruction of one of the initial functions is possible if the other function and the convolution are known. Such a procedure is called deconvolution [3]. In other words, deconvolution is the inverse mathematical operation of convolution:

$$
(f * g)+\epsilon=h,
$$

where $h$ is the resulting signal, $f$ - the renewable signal, $g$ - the interference signal, but describes noise. Deconvolution can also be achieved by dividing the convolution spectrum by spectrum of the known initial function. This in turn produces spectrum of the other initial function, which can be transformed to time domain [1], [2].

Compressive sampling (compressed sensing, CS) is a signal sampling technique that allows representing a compressible signal $f(x)$ as signal $y(x)$ with sample count $n$ and $m$ respectively by use of easily implementable expression

$$
y(x)=A f(x)
$$

where $A$ is the so-called measurement matrix, but $y(x)$ is a measurement. As a result, $m \ll n$. For recovery of signal $f(x) \ell_{1}$-minimisation algorithms must be used [4].

To exploit CS, the measurement matrix $A$ must conform to specific rules and ensure specific properties [5]. The most important is the coherence property of the measurement matrix $A$ that determines how many elements measurement $y(x)$ should contain to allow for perfect recovery of $f(x)$.

\section{PROPOSED METHODS}

Based on the theory, three methods for detecting the positions of volumetric defects in thin film coatings on a given glass sample were proposed. 
The first method utilises a direct algorithm of convolution, where function $f$ represents normalized translucency of the sample but function $g$ represents normalized visibility function of the sensor. This model uses a one-pixel sensor for detection of light passing through the sample. For ease of mathematics, a cosine was chosen to represent the sensor visibility function.

The mechanics of this model is as follows: the sensor is set at known distance $h$ from the sample and the sensor viewing angle $\alpha$ is known.

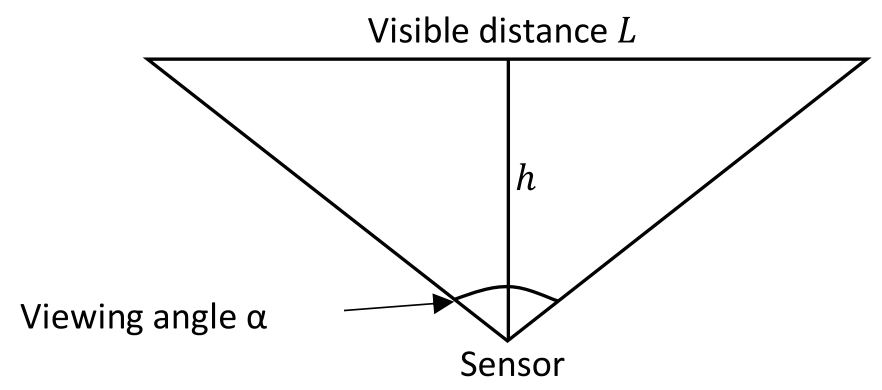

Fig. 1. Schematic of visibility distance calculation.

Mathematically, the visible distance L is calculated by equation

$$
L=2 \sqrt{\left(\frac{h}{\sin \left(\frac{\alpha}{2}\right)}\right)^{2}-h^{2}}
$$

In Fig. 1 the line $L$ representing the visible distance can be imagined as a conveyor. In the mathematical model, it is realized by a one-dimensional array with length $L$, which represents the sample translucency function $f(L)$. Initially, all elements are set to one, representing a fully translucent medium with no sample present. Next the viewing angle alpha is expressed in radians and used in cosine calculations to construct the visibility function $g(L)$. When the measurement process starts, iteratively the convolution of functions $f(L)$ and $g(L)$ is calculated, thus simulating a conveyor to move the sample precisely by one unit (size of defect). If there are no more sample coefficients available, the first value of $f(L)$ is set to one, thus representing a situation where the sample is about to pass the sensor. This way, for the last iteration $f(L)$ is uniformly equal to one, therefore returning to the initial state.

To detect the position of a volumetric defect it is necessary to calibrate the system. This is done by simulating a result from a sample with no defects. The calibrated measurement is compared to the measurement of the sample by subtracting them. The position of the first nonzero element represents the position of a volumetric defect in the sample. This algorithm of position detection works only to find the position of the first defect. This is not suitable if all defects need to be accounted for; however, this method is applied for such purposes. The key is to recalculate calibration each time a defect is found by introducing the said defect in the calibrated measurement.

The second method is based on the Fast Fourier Transform (FFT) and spec- 
trum properties of convolution. The experimental setup is the same as for the first method, to produce convolution, which corresponds to a measurement. To recover the original $f(L)$ function, spectrum of the measurement must be divided by spectrum of $f(L)$, and transformed to time domain by inverse FFT. By doing this, the translucency function of the sample within a visibility range is recovered. By repeating this process iteratively and recording results in order, it is possible to reconstruct the whole sample. Moreover, this method is easily performable in two-dimensional (2D) setting. To do this the visibility function must be expanded in 2D, representing a surface of a cosine and the "conveyor" system must be changed so that the sample is moved in $2 \mathrm{D}$ through the visibility range.

The third method. In a 1D case of the third method, convolution of a given signal $f(x)$ with convolution kernel $g(x)$ variously shifted in time can be implemented by using (4) so that signal $f(x)$ can be reconstructed by the method used in compressed sensing: $\ell_{1}$-minimisation. The third method uses similar mechanical setup as described previously; however, a multiple pixel sensor is used and during measurement, the conveyor is stationary, since there is no need to shift the sample. It is assumed that all pixels have a similar visibility function that is cut at both sides (1D case) of measurement system by use of black walls (see Fig. 2).

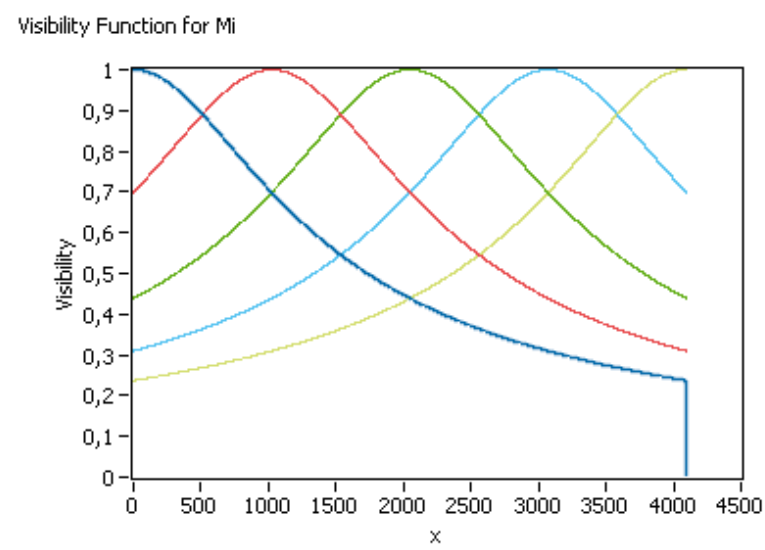

Fig. 2. Visibility function of 5 imaging pixels.

To use compressive sampling signal recovery methods, the signal has to be sparse or has to have a sparse representation [6]. Yet in a 1D case of a semi-translucent sample, the signal $f(x)$ will not be sparse. Nevertheless, the compressive sampling methods can be used if signal $f(x)$ has in time (or in this case along 1D axis) a constant value $a$ with some (sparse) places where signal is 0 . If this is the case, a sparse function $f^{\prime}(x)$ can be found

$$
f(x)=1-f^{\prime}(x) \rightarrow f^{\prime}(x)=a(x)-f(x),
$$

where $a(x)=\{a, \ldots, a\}$. Placing $f(x)$ in (4) will give

$$
y(x)=A\left(a(x)-f^{\prime}(x)\right)=A a(x)-A f^{\prime}(x) .
$$


It means that the sampled signal $y(x)$ will contain some constant $a A_{i}$ in each measurement $i$, where $A_{i}$ is row $i$ of $A$. The $\sum_{j} A_{i j}$ can be called amplification factor of $i^{t h}$ measurement. To find $f(x)$ using (6) the sparse $f^{\prime}(x)$ has to be found from

$$
A a(x)-y(x)=A f^{\prime}(x) \text {. }
$$

To recover signals that are compressible but not sparse in traditional sparsifying transformations from measurements $y(x)$, the sampling system has to register the described signal value $a$. Similarly, formulas can be developed for these kinds of signals if the minimum of the signal is some constant b. Moreover, if this signal has in time (or dimension) changing value of maxima (minima) $a(x)=F(x)$, where $F(x)$ is some known function, the compressive sampling technique still can be used to sample the signal.

It follows that maximum, minimum or exact values of coated sample translucency are not important for modelling, which allows simplifying the experiment using 1 to represent translucency of a sample value without a defect and 0 for defects.

\section{EXPERIMENTAL RESULTS AND DISCUSSION}

For modelling, testing and simulations, the National Instruments graphical programming environment "LabVIEW" was used. Due to time and processing power constraints, simulations were limited, yet a sufficient amount of information was gathered to perform the statistical analysis.

The first method's front panel is shown in Fig. 3. For simulation and result analysis, a 100 coefficient long sample $(100 \mu \mathrm{m})$ was used. The sensor viewing angle was swept from 1 to 160 degrees, the translucency of a defect was swept from 0 to "No defect" while the sensor distance to the sample (h) was swept from 1 to 100 units. For calculations, a numeric type "double" consisting of 64 bits was used. By analysing results, it was determined that the position of a volumetric defect was found correctly in approximately $76 \%$ of cases; however, in the remaining $24 \%$ of cases the position detected was \pm 1 unit off. In these $24 \%$ of cases, the resolution of calculations (64 bits) was not sufficient to detect a change in results.

To test the second method, two LabVIEW projects were created: for a onedimensional case and for a two-dimensional case, respectively.

For simulation and result analysis, a 100 by 100 coefficient sample was used, the sensor viewing angle was swept from 1 to 160 degrees, and the sensor distance to the sample (h) was swept from 1 to 100 coefficients. From one to five randomly placed volumetric defects with varying translucency were introduced in the sample.

After data analysis an unexpected result was found; in a one-dimensional case, results, both for one and multiple volumetric defect samples, showed that the positions of the defects were found correctly (as well as the translucency values were within $1 \%$ error margin) only in $52 \%$ of cases. For the rest $48 \%$ of cases, the translucency value was rapidly oscillating for every other position in the sample. However, in a two-dimensional case the spectrum multiplication method found all volumetric defects correctly and returned full translucency function within $1 \%$ tolerance in $98.6 \%$ of time for the case with 1 volumetric defect and $97.3 \%$ of time 
for the case with multiple volumetric defects. This indicates that there can be a bug in the algorithm for a one-dimensional case or some (small) parameter causes the algorithm to work incorrectly.

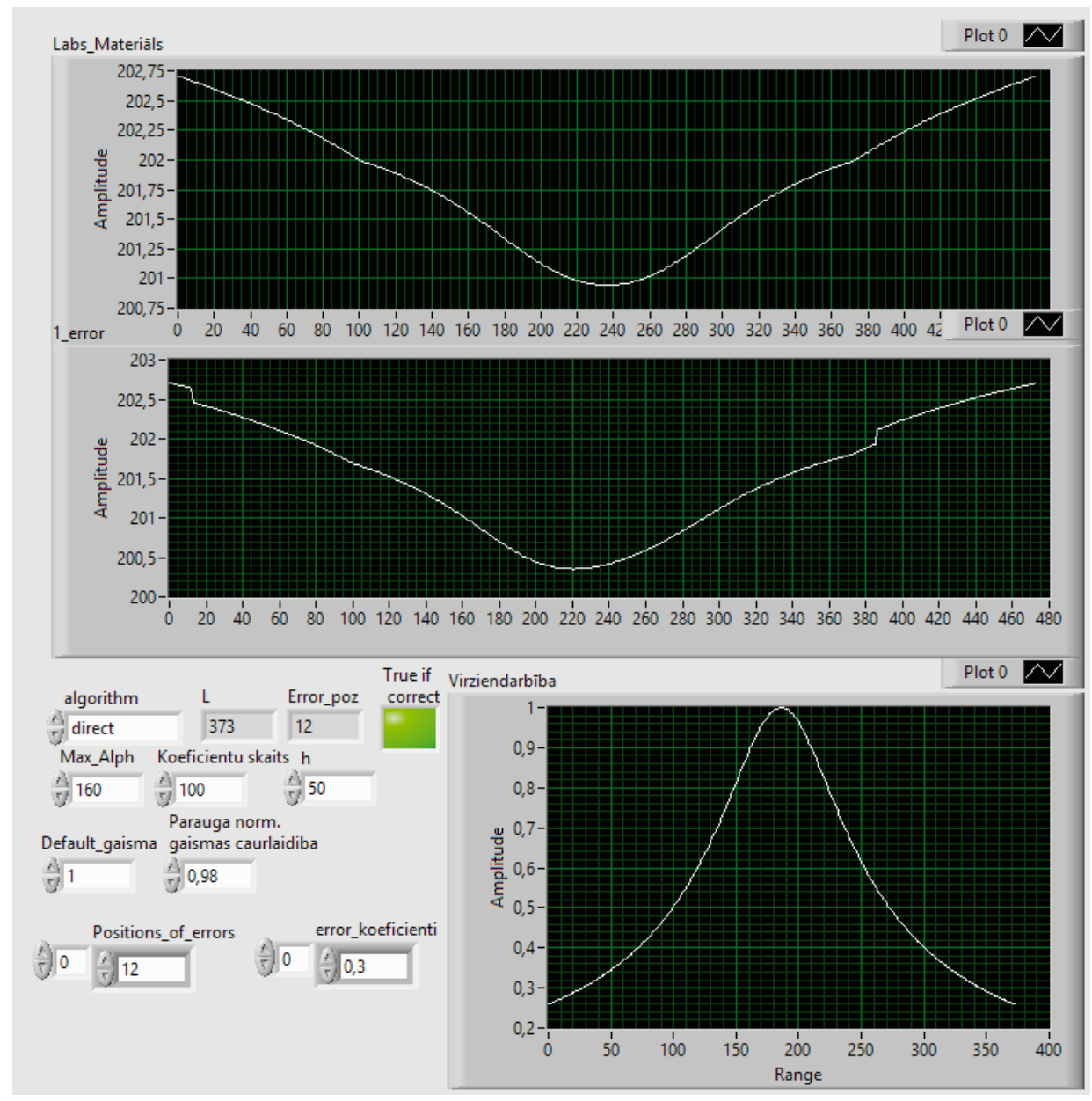

Fig. 3. Front panel example of Simple_Method.

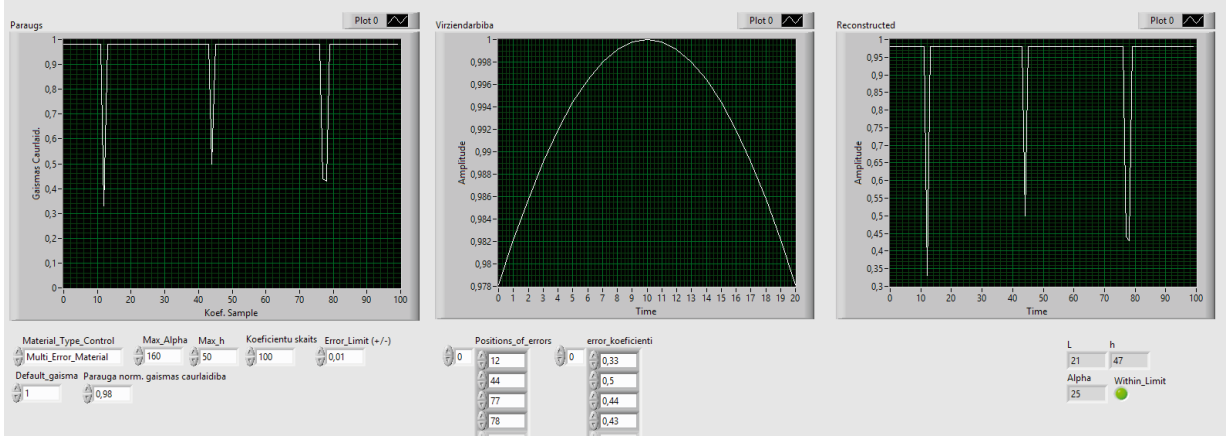

Fig. 4. Front panel of simulation using 1D FFT. 


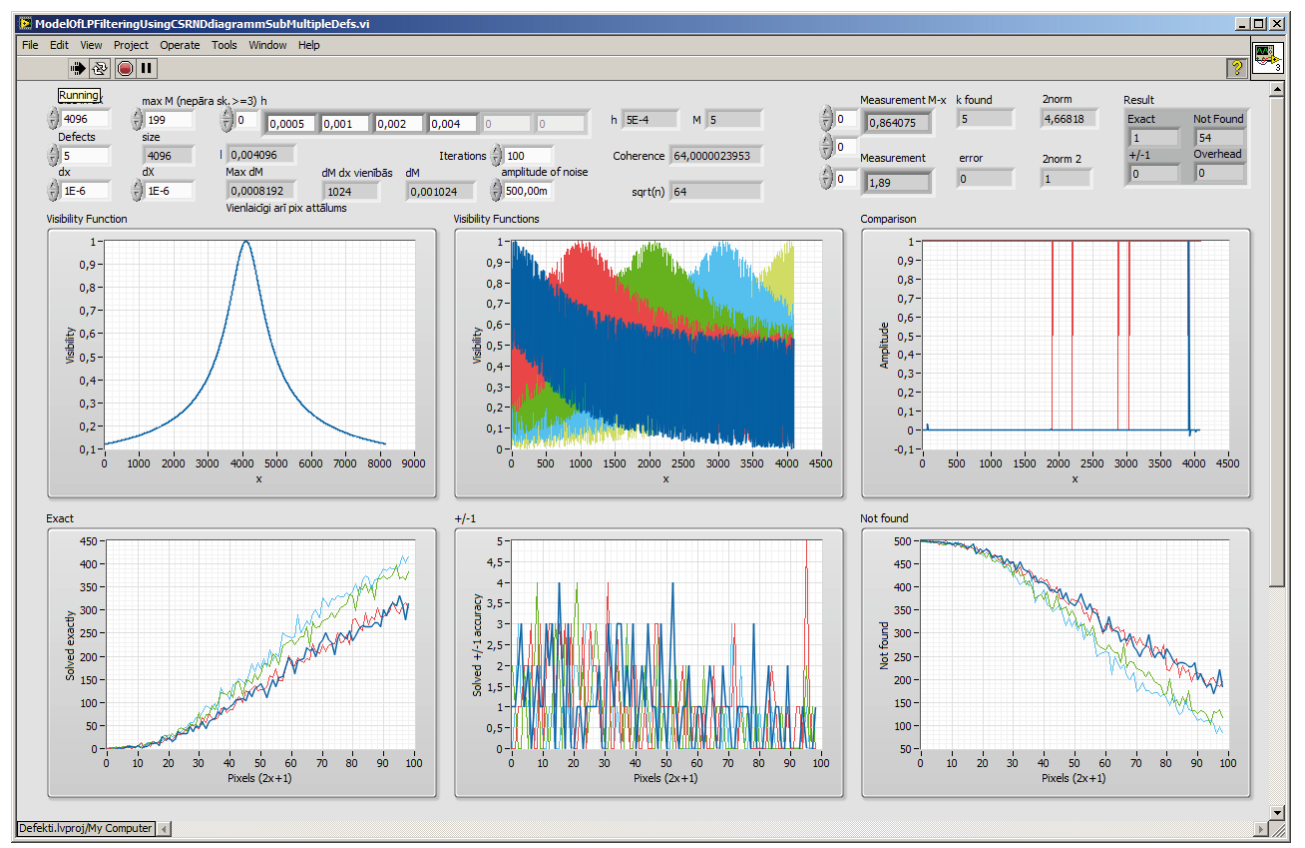

Fig. 5. Front panel of compressive sampling simulation.

The third method (see Fig. 5) was tested by using 1024 to 4096 coefficient samples possessing one to five volumetric defects with translucency value 0 set at random places for multi-error samples and all possible places in case of one defect. Sensor distance to sample $(h)$ was swept from $0.5 \mathrm{~mm}$ to $1 \mathrm{~cm}$. Additional simulation with $h=10$ to $25 \mathrm{~cm}$ was carried out for samples with only one volumetric defect testing all possible positions of defects. This method correctly returned position of the volumetric defect in $100 \%$ for the following defect cases: for $0.5 \mathrm{~mm}$ to $1 \mathrm{~cm}$ if the sensor had 3 to 99 pixels, for $h=10 \mathrm{~cm}$ if the sensor had less than 7 pixels (in this case, an increase in pixel count produced worse results, possibly due to error accumulation during calculations).

At first, this method failed to find multiple defects since measurement matrix $A$ was highly coherent; therefore, each pixel visibility function was randomised (see Fig. 5 graph "Visibility Functions"), thus adding white noise (with adjustable amplitude) to the pixel visibility function (see Fig. 5 graph "Visibility Function"); afterwards the summarised visibility function was normed. Physically this means that the sensor should be illuminated through a glass with random thickness pattern. As a result, coherence of $A$ did not improve much (see Fig 5. value "Coherence"), yet simulation was able to find multiple defects. Simulations with randomised visibility functions and 4096 unit samples produced the following results: for samples with one volumetric defect, $h \leq 25 \mathrm{~cm}$ and sensor with 5 to 99 pixels the model found defect when the added random noise level was as low as $0.01 \%$. In case of samples with 5 volumetric defects it can be seen that an increase in pixel count and decrease in distance improve defect detection accuracy (see Fig 5. graphs "Exact", " \pm 1 ", "Not found"); results were calculated for rather unrealistic randomisation of visibility function (added noise amplitude $50 \%$ ). Additional calculations showed 
that by increasing sensor pixel count the randomisation of the visibility function could be reduced.

Performance and memory. A computer with 64 bit operating system, 4 GB of RAM and Intel Pentium T4500 processor (dual core, $2.3 \mathrm{GHz}$ ) was used to carry out simulations. In case of the first method, it takes approximately 50 milliseconds for this system to perform a measurement, which uses, on average, $8.9 \mathrm{kB}$ of memory per measurement of $100 \mu \mathrm{m}$ sample. In a 1D case of the second method, it takes approximately 86 milliseconds for this system to perform a measurement using, on average, $4.2 \mathrm{kB}$ of memory per measurement. In a $2 \mathrm{D}$ case of the second method, the system uses approximately 1.7 seconds and, on average, 19.3 MB of memory per measurement. Although these numbers are significantly higher than for other cases, they are quite remarkable, since these measurements produce full translucency information of $2 \mathrm{D}$ visibility range. The measurement time needed for the third method is linearly dependent on a number of sensor pixels and sample defect count. In case of 99 pixels, for this system, to find one defect it takes approximately 6.1 milliseconds; however, in case of 49 pixels it takes only 3.2 milliseconds. On average, the third method uses $2.15 \mathrm{MB}$ of memory per measurement.

\section{FEASIBILITY OF DEFECTOSCOPE}

Digital images are dependent on performance of an imaging sensor. Two widely used sensor types are CCD (Charge-Coupled Device) and COMS (Complementary Metal-Oxide-Semiconductor). Although CMOS is a newer, cheaper and more power-efficient sensor, a CCD sensor would be more appropriate for application in a defectoscope. This is so due to inherent CMOS problem called rolling shutter. The so-called rolling shutter means that the sensor is read line by line, thus skewing a moving object such as in case with a conveyor above the sensor. In case of CCD, the whole image is captured at once as well as the analogous nature of CCD can provide a higher definition if appropriate circuitry is used [7], [8].

Digital image consists of two parts - usable signal and noise, which is an integral part that arises from different sources. Three main noise sources are identified: photon noise, read-out noise and dark current noise. Listed sensor noise parameters dictate a signal-to-noise ratio (SNR). SNR value of the sensor can be determined by expression

$$
S N R=\frac{P Q_{e} t}{\sqrt{(P+B) Q_{e} t+D t+N_{r}^{2}}}
$$

where $P$ is photon flux, $B$ is background photon flux (both given in photon/pixel/ $\mathrm{sec}), Q_{e}$ stands for quantum efficiency of CCD, $t$ is exposure or integration time but $D$ is dark current. From [9], [10] it is determined that the first and second models working with 64 bit values provide an SNR value of approximately $290 \mathrm{~dB}$. Best CCD sensors provide SNR up to $120 \mathrm{~dB}$ [6], [7] which corresponds approximately to 30 bit resolution; therefore, practical test would be necessary to determine the real life accuracy of the discussed methods. Further experiments would be necessary to 
determine an SNR value provided by the third model; however, it is well known that noise has a little effect when compressive sampling is used [11].

In construction of a defectoscope that utilises the proposed methods, a precise conveyor capable of moving exactly at 1 micron intervals is needed for the first and second methods, but a precision laser measuring system must be implemented for the third method. To achieve the best possible results, the sensor must be positioned as close to the sample as possible (less than $1 \mathrm{~mm}$ ).

\section{CONCLUSIONS}

All three investigated methods are capable of detecting micron scale volumetric defects in thin film coatings on glass substrates. However, each method provides different degree of accuracy and performance, thus, different potential application.

The first method is the simplest one and, potentially, the easiest to implement, since only one measurement of voltage is needed per movement of the conveyor. Yet this is also the least accurate method.

The second method needs more computing resources, however, could prove to be suitable in research setting where a full translucency analysis of the sample can be useful.

In manufacturing setting, the third method would be the most appropriate, since it is the fastest and most accurate in detecting position of one volumetric defect at quite large distances (up to $25 \mathrm{~cm}$ ) as well as it needs a simple imaging sensor and only moderate computing power.

In the multiple defect case of the third method, a special glass with randomised thickness must be placed before the sensor; its complexity defines pixel count in the sensor; visibility function randomisation of $33 \%$ allows finding more than $60 \%$ of defects at a sample distance of $1 \mathrm{~mm}$ in case of 199 pixel sensor. Doubling the pixel count can effectively reduce complexity of the glass, thus increasing the detection accuracy and allowing higher sensor distance to sample.

Computing hardware for the third method can effectively be implemented in FPGA due to parallel signal processing capabilities of this technology.

Further work will be continued to study result stability of CS approach versus noise of imaging matrix and ADC bit count. Practical research is needed to test real world applicability of the proposed methods in development of a defectoscope.

$$
\text { ACKNOWLEDGEMENTS }
$$

This research is financed by the European Regional Development Fund project (No.L-KC-11-0006) research 2.3. "Research in Thin Film Coating Technologies".

\section{REFERENCES}

1. Gonzalez, R. C., and Woods, R. E. (2008). Digital Image Processing. NJ: Pearson Prentice Hall. 
2. McClellan, J. H., Schafer, R. W., and Yoder, M. A. (2003). Signal Processing First. NY: Pearson Prentice Hall.

3. Microscopy Resource Centre (2012). Introduction to Deconvolution. Available at http:// www.olympusmicro.com/primer/digitalimaging/deconvolution/deconintro.html.

4. Donoho, D. L. (2006). Compressed sensing. IEEE Transactions on Information Theory 52(4), 1289-1306.

5. Candès, E.J., and Romberg, J. (2007). Sparsity and incoherence in compressive sampling. Inverse Problems 23, 969-985.

6. Gaigals, G., Greitans, M., and Andziulis, A. (2013). Compressive sensing: Analysis of signals in radio astronomy. Baltic Astronomy, 22, 347-361.

7. Photometrics. (2010). Keep the Noise Down. Available at http://www.photometrics.com/ resources/technotes/pdfs/snr.pdf.

8. Microscopy. CCD Signal-to-Noise Ratio. Available at http://www.microscopyu.com/tutorials/java/digitalimaging/signaltonoise/.

9. National Instrument. (2012). Numeric Data Types Table. Available at http://zone.ni.com/ reference/en-XX/help/371361J-01/lvhowto/numeric_data_types table/.

10. Russ, J. C. (2011). The Image Processing Handbook. UK: CRC Press.

11. Fornasier, M., and Rauhut, H. (2011). Compressive sensing. Handbook of Mathematical Methods in Imaging (pp. 187-228). NY: Springer.

\title{
MATEMĀTISKO MODELUU IZSTRĀDE MIKRONA IZMĒRA TILPUMA DEFEKTU DETEKTËŠ̉ANAI PLĀNO KĀRTIN̦U PĀRKLĀJUMOS
}

\author{
G. Gaigals, M. Donerblics, G. Dreifogels
}

Kopsavilkums

Aprakstītais darbs ir saistīts ar matemātisku metožu izstrādi viena mikrona izmēra tilpuma defektu pozīciju noteikšanai stikla paraugiem, kas pārklāti ar plānajām kārtiņām, izmantojot attēlformēšanas paņēmienus, bet izvairoties no dārgām optiskām iekārtām, piemēram, lēcām.

Tika izstrādātas trīs metodes šādu defektu pozīciju noteikšanai, dots šo metožu apraksts. Metožu pārbaudei izveidoti simulāciju modeḷi National Instruments grafiskās programmēšanas vidē LabVIEW.

Rakstā salīdzināti ar katru metodi iegūtie rezultāti, metožu precizitāte, àtrdarbība un implementācijas īpatnības. Iezīmēts turpmāko pētījumu virziens.

16.11.2015. 